\title{
O MARKETING DE GUERRILHA COMO FERRAMENTA ESTRATÉGICA: UMA ANÁLISE DA APLICABILIDADE EM EMPRESAS DE MICRO E PEQUENO PORTE EM TEMPOS DE PANDEMIA
}

\author{
Guerrilla Marketing as a Strategic Tool: an analysis of its applicability in \\ micro and small enterprises in pandemic times
}

\author{
Manoel João Ramos ${ }^{1}$; Paulo César da Silva Ilha²; Cleiton Rodrigo Hansel ${ }^{3}$; \\ Alan Gabriel Kappes Camargo ${ }^{4}$; Daiane Thaís Krindges ${ }^{4}$
}

\begin{abstract}
${ }^{1}$ Doutor em Recursos Pesqueiros e Engenharia de Pesca; Mestre em Desenvolvimento Regional e Agronegócio; Universidade Estadual do Oeste do Paraná, Câmpus de Toledo, PR. E-mail: eng.major@ hotmail.com

${ }^{2}$ Doutor e Mestre em Desenvolvimento Regional e Agronegócio; Universidade Estadual do Oeste do Paraná, Câmpus de Toledo, PR.

${ }^{3}$ Especialista em Cooperativismo e Agronegócio; Administrador de Empresas; Faculdade de Ensino Superior de Marechal Cândido Rondon, ISEPE/Rondon.

${ }^{4}$ Bacharel em Administração; Faculdade de Ensino Superior de Marechal Cândido Rondon.
\end{abstract}

Data do recebimento: 15/09/2020 - Data do aceite: 20/04/2021

RESUMO: Este estudo apresenta uma análise das estratégias de marketing de guerrilha utilizadas em ações mercadológicas pelas micro e pequenas empresas do varejo de vestuário instaladas no município de Mercedes-PR, em plena pandemia do COVID-19, sendo estudado o período de março a julho de 2020. A metodologia utilizada foi de cunho exploratório, com amostragem de $88 \%$ das empresas do setor. Utilizou-se como técnica de levantamento dos dados a pesquisa tipo Survey com a aplicação de questionário via Google For$\mathrm{ms}{ }^{\circledR}$. Embora exista vasta literatura sobre as diversas vantagens das ações de marketing de guerrilha, especialmente para empresas menores ou com pouca verba publicitária, pois este tipo de marketing exige um menor volume de recursos financeiros e não exige níveis elevados criatividade e conhecimento para criar ações inteligentes e gerar bons resultados, observa-se que a maior 
parte das empresas pesquisadas (66\%) não fazem o uso dessa estratégia, tornando-se mais vulnerável, principalmente em tempos de crise, quando os recursos financeiros se tornam mais escassos, demandando maior criatividade.

Palavras-chave: Marketing de Guerrilha. Micro e Pequenas Empresas. COVID-19.

\begin{abstract}
This study presents an analysis of the guerrilla marketing strategies used in marketing actions by micro and small clothing retail companies located in the municipality of Mercedes-PR, in the COVID-19 pandemic time, being studied from March to July 2020. The methodology used was exploratory research, with a sample of $88 \%$ of companies in the sector. A data search technique type research Survey was used, with the application of a questionnaire via Google Forms ${ }^{\circledR}$. Although there is a vast literature on the various advantages of guerrilla marketing actions, especially for smaller companies or those with little advertising funds, as this type of marketing requires a lower volume of financial resources and does not require high levels of creativity and knowledge to create intelligent and generate good results, it is observed that most of the companies surveyed (66\%) do not use this strategy, becoming more vulnerable, especially in times of crisis, when financial resources become scarcer and demand greater creativity.
\end{abstract}

Keywords: Guerrilla Marketing. Micro and Small Companies. COVID-19.

\section{Introdução}

O fenômeno da globalização progride a um ritmo incontrolável e experimenta um tempo que ainda pode ser considerado como a Era da Informação, caracterizada pela popularização da internet e da inserção das novas tecnologias. Em virtude do desenvolvimento da tecnologia, do impacto da ciência e dos sistemas de comunicação, o mundo torna-se pequeno e interdependente. As indústrias como genética, robótica, nanotecnologia, inteligência artificial e informática se tornam, a cada dia, mais relevantes nesse contexto. Isso implica em modificações sociais, culturais, comportamentais e de consumo a diferentes mercados e setores da economia e no mundo dos negócios, inclusive no marketing.
Ao considerar o contexto de uma sociedade saturada de informação, o maior risco que uma organização pode enfrentar é ser ignorada. Desta forma, as empresas precisam fugir da zona de conforto e ampliar suas vantagens competitivas. Nesse sentido, a proposta do marketing de guerrilha consiste em furar o congestionamento ou o bloqueio do mercado, onde milhares de produtos "clamam" por atenção e posicionamento de suas marcas na rua, lado a lado e de frente com o seu consumidor.

O marketing de guerrilha vem ganhando destaque no cenário mundial, principalmente, no atual contexto de pandemia provocada pelo COVID-19, que vem assolando as economias e provocando colapso financeiro, tornando os recursos cada vez mais escassos, especialmente para os investimentos em publicidade. 
Desta forma, o marketing de guerrilha se configura em uma estratégia que possibilita a redução de custos e se torna uma boa alternativa para a divulgação de empresas e marcas que possuem recursos financeiros limitados, já que a guerrilha se utiliza de estratégias pouco convencionais e formas básicas de comunicação, envolvendo mídias de baixo custo, tais como o uso de adesivos, grafites, ações de corpo-a-corpo, shows e ofertas relâmpagos, merchandising no ponto de venda, projeções, entre outras, em que a criatividade, ousadia, inteligência e planejamento são mais importantes que o dinheiro.

Em um mercado cada vez mais complexo, as empresas precisam inovar nas suas estratégias competitivas de marketing para sobreviverem. Neste aspecto, este estudo busca responder a pergunta: como as micros e pequenas empresas têm utilizado estratégias de marketing direto e de guerrilha para ampliar a sua competitividade frente à grande concorrência, em um momento de crise pandêmica?

O desenvolvimento do estudo se justifica pelo fato de que, enquanto as atividades de marketing de guerrilha podem ser vistas, cada vez mais, na prática empresarial, o fenômeno, às vezes, é discutido com alguma controvérsia na ciência do marketing, sendo, por não raras ocasiões, completamente negligenciado na literatura científica de marketing, quando de fato, a proposta do marketing de guerrilha é realizar ações de alto impacto na sociedade, com o envolvimento de poucos recursos econômicos.

Por fim, este trabalho apresenta alguns casos de marketing de guerrilha e esclarece a relevância que este tipo propaganda vem ganhando diante das mídias convencionais e, mostra, também, que este tipo de ação não é apenas uma tendência, mas um importante aliado ao pequeno empresário que tem seus recursos limitados. No entanto, é salutar esclarecer que este tipo de estratégia não é apenas recorrente quando se trata de pequenas empresas, pois grandes e reconhecidas marcas, com orçamentos de marketing abundantes, adotam este tipo de abordagem para a obtenção de vantagens competitivas, se posicionar no mercado e fixar sua marca e imagem perante os consumidores e na sociedade em que estão inseridos.

\section{Fundamentação teórica}

A definição de marketing é muito ampla e tem, entre outros significados, a ação mercadológica, não sendo utilizada apenas para o incremento de vendas, mas também para ampliar os parâmetros em todos os processos de troca.

$\mathrm{Na}$ área do marketing, concentra-se análises competitivas, do mercado ou comportamento dos consumidores, onde inclui um perfil e análise dos consumidores, definindo os segmentos do mercado, elaborando plano de marketing, onde são utilizados pelas organizações, com decisões nas relações do preço, do produto, da distribuição e da comunicação, bem como a administração de vendas (ROESCH, 1996).

O terno é bastante conhecido como Market, que tem na sua tradução o significado de "mercado". Assim, observa se que a nomenclatura marketing se traduz em mecanização, mercadológica ou então de comercialização, que enquadra nos estudos de como lidar com o mercado. A definição de marketing pode ser um processo de planejamento e execução, iniciando com a concepção e a obtenção de um orçamento adequado, promoções e, desta forma, possibilitar a distribuição das ideias de produtos ou serviços, com o objetivo de facilitar as trocas (COBRA, 2010).

Conforme destaca Kotler e Keller (2006), muitas vezes, o objetivo das ações de marketing pode estar atrelado à ampliação das vendas, conquista de mercados, entre outros fatores. Entretanto, o autor salienta que: 
O marketing possui o objetivo de tornar mais supérfluo os esforços de venda do produto. A finalidade do marketing é o de conhecer e de entender o seu cliente, a ponto de que o produto ou serviço seja mais adequado e passe a vender sozinho. Assim, o marketing deve resultar num cliente disposto para comprar (KOTLER; KELLER, 2006, p.4).

Segundo Dornelas (2005, p. 150), “as estratégias de marketing são os meios e os métodos que a empresa deverá utilizar para atingir seus objetivos". O autor acrescenta que a projeção de vendas de uma organização está diretamente relacionada à sua estratégia de marketing, que define o posicionamento no mercado, a política de preços, as promoções, dos canais de venda que serão adotados, bem como, as formas de o produto atingir o cliente.

\section{Marketing direto ou tradicional}

O marketing direto tem em sua definição nos meios de comunicação, na qual, é utilizado em todas as necessidades de cada consumidor, visando a cultivar um relacionamento saudável entre o consumidor e a empresa.

De forma complementar, o marketing direto também pode ser definido como:

a comunicação dirigida de oferta, para um público-alvo prioritário, com resposta direta, quantificável e mensurável. É um sistema de mídia e métodos designados a estimular a resposta de um prospect ou cliente com intuito de desenvolver ou aumentar o relacionamento com o cliente (KARKOTLI, 2008, p. 33).

Para Ferrarezi (2016), o marketing tradicional é aquele que abrange todos os atos de venda. É ele quem cria todo material publicitário, como brindes, anúncios em revistas e jornais, entre outros, fazendo com que o marketing seja em apenas um instante. Observa-se que uns dos principais objetivos do marketing direto consiste na elaboração de uma pesquisa do mercado, com o intuito de identificar os anseios do consumidor, buscar ideias para que os consumidores passem a adquirir os produtos ou serviços da empresa, fidelizar estes consumidores e, assim, ampliar a rentabilidade nas vendas.

Com base nos argumentos de Dias et. al. (2003), as empresas buscam uma abordagem com os clientes na intenção de provocar uma individualização ou um contato mais personalizado, em que a mensagem transmitida está voltada para uma pessoa específica.

Compartilhando dessa mesma opinião, Kotler (1988) e Pires (1995) defendem que as ações de marketing, para serem bem-sucedidas não devem ser destinadas ao mercado em sua totalidade, mas sim a um público específico. Assim, a seleção dos mercados-alvo revela-se uma questão indispensável, ou seja, direcionar-se para todos e atuar em todos não é a melhor opção. Isso implica no fato de que o empreendedor necessita conhecer as necessidades para quem são dirigidas a suas atividades de marketing. Neste aspecto, de modo a combater este bombardeamento por mensagens publicitárias similares de produtos e serviços pouco distintos, torna-se essencial recorrer a algo que se destaque, que desperte a atenção do público-alvo. Uma possível solução para este problema perpassa por uma maneira diferente de comunicação, criativa, original e inovadora, como a estratégia de marketing de guerrilha.

\section{Marketing de guerrilha}

A expressão marketing de guerrilha foi criada pelo publicitário norte-americano Jay Conrad Levinson, com a publicação do livro "Guerrilla Marketing Attack", em 
1982. A expressão foi inspirada, justamente, na guerrilha bélica e o seu criador defende que pequenas e médias empresas podem e devem competir no mercado com as grandes companhias, mediante o emprego de armas mais eficazes, baseadas na criatividade e na inovação.

Desta forma, o uso das ferramentas de marketing de guerrilha tem como objetivo o combate aos grandes competidores ou simplesmente a sobrevivência das pequenas empresas, em um ambiente de alta competitividade.

Nas palavras de Dantas (2009, p.8)

[...] "guerrilha" significa, ao pé da letra, uma "pequena guerra". Trata-se, em sua origem, de um tipo de guerra não convencional, cujo principal artifício é a ocultação e a extrema mobilidade dos guerreiros, denominados, neste caso, "guerrilheiros". A grande tática que está por trás de uma guerrilha é a ação psicológica, que se impõe sobre as forças militares, fazendo com que os adversários considerados mais fortes sejam vencidos.

Desde os primórdios dos tempos, a expressão guerrilha tem sido utilizada para nomear pequenos exércitos que, no intuito de compensar a sua inferioridade numérica e reduzido poder bélico, utilizavam-se de táticas de guerra não convencionais, para surpreender o inimigo e assim, facilitar o combate.

Na visão de Barbosa (2007), é possível que a mais famosa das guerras em que foram empregadas táticas de guerrilha ocorreu em 1965, no Vietnã, onde o então soberano Estados Unidos, após de ter investido em torno de 250 bilhões de dólares em despesas com armas de alto poder destrutivo e tinha ampla maioria em número de combatentes, sofreu uma humilhante derrota para os vietnamitas, que possuíam poder bélico inferior, com armas visivelmente ultrapassadas, se com- parado ao poder de fogo norte-americano (BARBOSA, 2007).

No contexto mercadológico, o marketing de guerrilha surge como uma resposta das pequenas empresas à sua deficiência e capacidade financeira para criar e gerenciar grandes ações de marketing. Para Levinson et al. (2007), a alma do marketing de guerrilha consiste na utilização adequada de técnicas que assumem o papel crucial de uma campanha. As ferramentas para isso são inúmeras e distintas, no entanto, o sucesso atende à eliminação de armas que falharam ou desviaram-se do alvo pretendido, contornando a situação com o emprego de técnicas mais apropriadas. Nesse aspecto, Hill e Rifkin (2002) compartilham da mesma opinião, ao ressaltar que este marketing alternativo respeita igualmente os princípios do marketing tradicional, pois tem o objetivo de identificar as necessidades dos clientes e fornecer soluções que correspondem a esses anseios.

O marketing de guerrilha não antagoniza com o marketing direto ou tradicional, porém, se apresenta como uma alternativa mais acessível, pois o marketing tradicional, geralmente, tende a consumir um elevado volume de recursos e, se mal planejado ou abandonado prematuramente, poderá não compensar o dispêndio de recursos financeiros. "Os marqueteiros de guerrilha não confiam na força bruta de um orçamento gigantesco, em vez disso confiam na força bruta da imaginação fértil" (LEVINSON, 2010, p. 22).

Neste sentido, é importante destacar que, contrariamente ao marketing tradicional, no marketing de guerrilha a empresa deve direcionar o seu foco para a criatividade e não para o volume de dinheiro a ser gasto. Nas palavras de Freire e Almeida (2006, p. 276):

[...] a estratégia é atacar o consumidor da forma menos esperada e convencional possível. E, geralmente, com um custo mais baixo do que a mídia tradicional. 
Usando as táticas de guerrilha bélica, que usa criatividade, foco e energia em vez de dinheiro.

Outro fator de grande relevância na estratégia de marketing de guerrilha, segundo Sun Tzu (2011), consiste no reconhecimento do campo de batalha. Isso implica em perceber a situação do adversário, avaliar as distâncias e compreender o grau de dificuldade do terreno, possibilitando assim, controlar e alcançar a vitória. Ademais, o autor ressalta que aquele que concentra mais esforços no sentido de obter um maior conhecimento do campo de batalha, reúne as melhores condições que o conduzem à vitória. Por outro lado, aqueles que não atentam a estes fatores serão, seguramente, derrotados.

Para Gart (2011), citado por Leite e Velhinho (2012), os consumidores possuem maior facilidade para recordar de uma ação de guerrilha do que as campanhas de marketing tradicionais, dado a acentuada distinção que se verifica entre ambas. Uma vez que o marketing de guerrilha provoca impacto, o público tende a comentá-la, expandindo assim, a publicidade boca-a-boca. Nesse aspecto, uma ação local alcança forças e visibilidade por meio de redes sociais e, por conseguinte, pela imprensa.

\section{Ferramentas do marketing de guerrilha}

Diversas são as ferramentas capazes de propiciar a competitividade perante os concorrentes, adquirir longevidade e uma extensa lista de clientes, como refere Levinson (1989). Neste aspecto, as ações de guerrilha se assentam em princípios sólidos, com elevados níveis de criatividade e imaginação, bastante paciência, muita sensibilidade, alguma persistência e uma certa dose de agressividade. $\mathrm{O}$ autor ressalta que quanto maior for o número de armas utilizadas por uma marca, mais eficaz será o ataque. Entretanto, somente as armas apropriadas ao negócio devem ser utilizadas, pois o mais importante é fazer uso do máximo de ferramentas possíveis, da forma mais inteligente possível, mas com uma estratégia clara e perceptível.

Nesse sentido, o estudo realizado por Leite e Velhinho (2012) destaca diversas ferramentas que servem de instrumento para a aplicação do marketing de guerrilha, algumas elencadas a seguir:

\section{Ambush marketing ou Marketing de em-}

boscada: infiltração voluntária de uma marca ou produto numa ação ou evento desenvolvido por uma segunda empresa. Esta infiltração inesperada cria ações invulgares, conquistando, assim, visibilidade na mídia, sem acarretar com quaisquer custos de difusão (SANDLER; SHANI 1989, citado por REIS 1996). Neste tipo de ação, a marca oficial efetua um elevado investimento no evento, com o intuito de promover a sua imagem, seus valores e seus produtos ou serviços, com vista a ampliar sua notoriedade. Entretanto, contrariamente ao seu desejo, o espaço é invadido por uma marca concorrente, beneficiando com todo o esforço e trabalho desenvolvido pelo oponente.

Astroturfing: incorpora um conjunto de ferramentas de guerrilha capazes de, por meio de ações distintas, chamar a atenção do público, sem recorrer a uma ação midiática como suporte essencial, na transmissão de uma mensagem publicitária. Conforme salienta Rodrigues (2010), esta estratégia consiste na mobilização de grupos constituídos por populares que, hipoteticamente, estão unidos na defesa de uma causa em que acreditam. No entanto, o desejo de uma empresa em promover sua marca ou produto se constitui na base deste movimento. 
Buzz Marketing: caracteriza-se por captar a atenção dos consumidores e da mídia, ao ponto de ser divertido, cativante e digno de notícia falar sobre a marca. Conforme observa Hughes (2006), esse tipo de estratégia inicia-se com o envio de mensagens a determinados consumidores, líderes de grupos de referência, pessoas admiradas pelo grande público e muito sociáveis, que irão divulgar a mensagem. Para Leite e Velhinho (2012), uma outra variante desta técnica consiste na entrega de amostras a pessoas influentes, no intuito de encorajá-las a comentar e avaliar os produtos em sua rede de contatos. Esta técnica cria um boca-a-boca, buzz, positivo em torno de um produto ou serviço, transformando consumidores selecionados em veículos espontâneos da mensagem.

Marketing Invisível: consiste em uma modalidade de guerrilha que tenta contrariar uma das principais causas de insucesso publicitário, o excesso de mensagens que chegam até o consumidor. Conforme destaca Fonseca (2011), esse tipo de estratégia busca diferenciar ou não se assemelhar à maioria das campanhas publicitárias, ou seja, o objetivo é envolver o consumidor ao ponto que este não perceba que se trata de uma ação de marketing.

PR Stunt: consiste na criação de uma história original, que seja impactante e, ao mesmo tempo, deslumbrante visando a estimular o interesse por parte da mídia e, assim, alcançar grande visibilidade e notoriedade da marca ou produto (CRUZ, 2010). Para Rodrigues (2010), a expressão $P R$ Stunt significa "Public Relations Stunt”, ou seja, é uma associação de Relações Públicas a truque ou proeza.

Marketing Viral: também conhecida como ideavirus, a estratégia consiste em espalhar uma ideia, marca, produto ou serviço, sem cansar os consumidores. O campo de atuação e contágio é a internet e seus distintos suportes - sites, e-mails, blogs e redes sociais, como Facebook e Twitter, de forma que a disseminação da mensagem seja rápida e abrangente ao maior número de pessoas possíveis. Há a necessidade de que a mensagem seja forte e apelativa, de conteúdo informativo e/ou divertido e, assim, despertar o interesse dos consumidores a contagiar outras pessoas, com a divulgação do seu produto ou serviço (LEITE; VELHINHO, 2012).

Performance: caracteriza-se pelo aproveitamento de espetáculos arrebatadores e insólitos que se realizam, tendencialmente, num espaço público. O principal objetivo nessa estratégia é promover a interação entre a empresa e o público-alvo e, assim, transmitir uma mensagem em forma de entretenimento e criatividade (LEITE; VELHINHO, 2012).

\section{Metodologia}

A investigação, apoiada na análise quantitativa de dados primários, se propôs a examinar de que forma e em que proporção, as micro e pequenas empresas de varejo do ramo de vestuário, estabelecidas no município de Mercedes, Paraná, se utilizam de estratégias de marketing de guerrilha para competirem num mercado cada vez mais acirrado e de forma sui generis, num momento de crise histórica, provocada pela pandemia de $\mathrm{CO}$ VID-19, em que o comércio local teve suas atividades, total ou parcialmente, impedidas de manterem suas portas abertas, no intuito de evitar a aglomeração de pessoas e, assim, minimizar a propagação do vírus, bem como os impactos negativos na saúde pública. Destarte, a investigação concentrou-se, prioritariamente, no período compreendido entre os meses de março e julho do ano de 2020. Segundo a Lei Geral da Micro e Pequena 
Empresa, a classificação dos negócios, com base na receita bruta anual define, como microempresas, aquelas que obtêm receita bruta anual, igual ou inferior a $\mathrm{R} \$ 360.000,00$, enquanto que as empresas de pequeno porte, são aquelas que apresentam receitas brutas anuais superiores às das microempresas e até R\$ 4.800.000.00 (SEBRAE, 2020).

Os procedimentos metodológicos utilizados para o desenvolvimento da pesquisa são, em sua essência, de cunho exploratório, que, segundo Gil (2009), tem o objetivo de proporcionar maior familiaridade com o problema, com vistas a torná-lo mais explícito. Para tanto, utilizou- se o método de pesquisa Survey, que de acordo com Silva et al. (1997, p. 410) trata-se de uma "coleta sistemática de informações a partir dos respondentes com o propósito de compreender e/ou prever alguns aspectos do comportamento da população em estudo". Para a obtenção dos dados e posterior análise dos resultados, elaborou-se um questionário eletrônico por meio da ferramenta Google Forms ${ }^{\circledR}$, contendo 20 (vinte) questões fechadas, o qual foi enviado via e-mail o link de acesso à home page do formulário, possibilitando, assim, que os proprietários das empresas respondessem e efetuassem o envio diretamente a partir do Google Forms ${ }^{\circledR}$, sem a necessidade de um retorno via e-mail.

Os links de acesso aos questionários foram enviados para os e-mails dos responsáveis pelas empresas objeto de estudo, após a obtenção de dados junto à Associação Comercial do município. O formulário foi enviado para todo o universo das 50 (cinquenta) micros e pequenas empresas do setor varejista do ramo de vestuário, incluindo atividades similares, como a venda de artigos de armarinho, instaladas no município, utilizando-se da técnica de levantamento do tipo censo, também conhecida como pesquisa de campo, a qual foi muito útil, nesse caso, pois proporcionou a obtenção de informações relativas a $88 \%$ da totalidade. Em termos de representação estatística o estudo contou com uma amostra de 44 (quarenta e quatro) empresários respondentes que atuam no setor investigado. Para calcular o tamanho da amostra para a sua validação, foi utilizada a fórmula de amostragem citada por Mattar (1996, p. 220) para uma população finita.

$$
\mathrm{n}=\frac{N \cdot Z^{2} \cdot p \cdot q}{E^{2} \cdot N+Z^{2} \cdot p \cdot q}
$$

Em que:

$\mathrm{n}=$ tamanho da amostra;

$\mathrm{N}=$ tamanho da população;

$\mathrm{Z}=$ valor padrão determinado pelo nível de confiança. Para o nível de confiança de $95 \%, Z=1,96$;

$\mathrm{p}=$ proporção de ocorrência da variável em estudo na população $(0,5)$;

$\mathrm{q}=$ proporção de não-ocorrência da variável em estudo na população $(q=1-p)$;

$\mathrm{E}=$ erro máximo admitido $(0,05)$.

$$
\begin{gathered}
\mathrm{n}=\frac{50 \cdot 1,96^{2} \cdot 0,5 \cdot(1-0,5)}{0,05^{2} \cdot 50+1,96^{2} \cdot 0,5 \cdot(1-0,5)} \\
\mathrm{n}=\frac{48,02}{1,0854} \\
\mathrm{n}=44,24
\end{gathered}
$$

Para o levantamento de dados foi utilizado um questionário previamente estruturado, com questões fechadas, contendo questões que retratem o entendimento, usualmente aceito, das sete ferramentas que servem de instrumento para a aplicação do marketing de guerrilha. Para a aplicação do questionário foi utilizado o instrumento Google Forms ${ }^{\circledR}$, que se trata de uma plataforma online, que permite a elaboração de um formulário, no qual é possível configurar e desenvolver um 
conjunto de questões de forma estruturada, seja com perguntas abertas ou objetivas e, assim, disponibilizá-lo online para os entrevistados (GOOGLE FORMS, 2020).

O instrumento foi escolhido, basicamente, pelo fato de ser considerado uma alternativa viável para a realização da pesquisa com todas as empresas, objeto de estudo, em um intervalo curto de tempo e, ainda, devido à pandemia do COVID-19 possibilitar, de forma eficaz, a aplicação do questionário sem prejuízo às medidas de distanciamento social impostas por decreto oficial, bem como considerar as dificuldades que muitas empresas deste segmento vêm encontrando para a manutenção de seu ritmo normal de trabalho.

Após a aplicação dos formulários online e a coleta dos dados estatísticos expressos em números pela plataforma do Google Forms ${ }^{\circledR}$, foi possível realizar o processamento e a tabulação dos dados em uma representação gráfica contendo os resultados da pesquisa em porcentagem, facilitando, assim, a sua análise.

\section{Apresentaçao e análise dos resultados}

Segundo Teixeira (2003) a apresentação e a análise dos resultados, consiste, basicamente, em dispor os dados coletados de uma forma clara e objetiva, que permitam a realização de uma análise conclusiva e elucidativa dos fenômenos investigados. O tópico é exposto em três etapas consecutivas e complementares, na qual, a primeira se encarrega de apresentar, especificamente, às empresas, no que tange ao seu ambiente de negócios; posteriormente, são apresentados os resultados que abrangem de uma forma mais direcionada as estratégias de marketing tradicional e, por fim, são apontados os resultados relativos às ações estratégicas de marketing de guerrilha.

\section{Ambiente de Negócios}

O ambiente de negócios em que estão inseridas as referidas empresas, pode trazer à luz uma importância significativa. As informações, aqui constatadas poderão estar influenciando a aplicabilidade ou não das estratégias de marketing de guerrilha.

$\mathrm{Na}$ primeira indagação, buscou-se informações sobre o tempo de existência das empresas no mercado mercedense.

Gráfico 1 - Tempo de existência da empresa

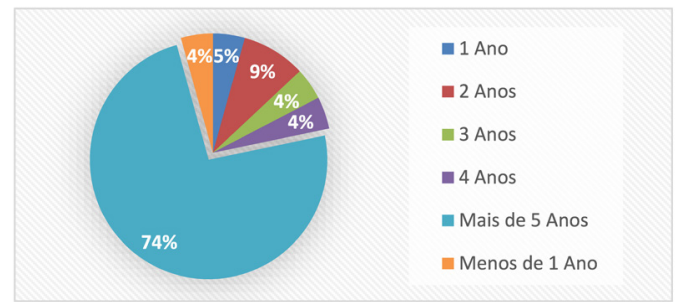

Conforme se observa no gráfico 1 , a maioria das empresas pesquisadas atuam há mais de cinco anos no município de Mercedes. Isso coloca em evidência o fato de que a maior parte das empresas pesquisadas possuem ampla experiência com a realidade do mercado e com o seu público consumidor. Isso possibilita, de forma mais eficiente, a prática e execução de seus negócios, além de proporcionar um conjunto de informações com potencial para retratar, com maior fidelidade, os dados colhidos e, por consequência, os resultados da pesquisa, trazendo-os mais próximos à realidade de todas as empresas do setor pesquisado.

A indagação seguinte tem por objetivo conhecer quais as características de gestão dos negócios, ou seja, se a empresa é de caráter familiar ou não, fazendo com que a empresa possa ser administrada para atingir os objetivos de maneira eficaz, valorizando 
o conhecimento e as habilidades das pessoas envolvidas na atividade. Conforme os resultados apontados no gráfico 2 , observa-se que $85 \%$ das empresas respondentes da pesquisa caracterizam-se pelo modelo de gestão familiar.

Gráfico 2 - Características das empresas

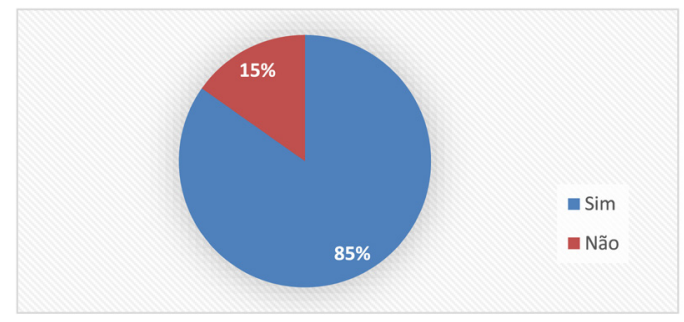

Em uma análise mais ampla, observa-se que as empresas familiares são a forma predominante de empresa em todo o mundo. Elas ocupam uma grande parte nas relações econômicas e sociais. Entretanto, as empresas familiares não são, necessariamente, empresas de pequeno porte ou microempresas, mesmo que isso seja uma tendência.

Neste sentido, a próxima indagação tem por intenção identificar qual o porte dessas empresas no município de Mercedes, apresentando-se como opções de micros e pequenas empresas, dado o objetivo inicial deste estudo, bem como as principais características do comércio local, considerando a classificação proposta pela Lei Geral da Micro e Pequena Empresa, já citada anteriormente, conforme o SEBRAE (2020).

Desta forma, observa-se no gráfico 3 , que a realidade do município de Mercedes retrata uma configuração do comércio varejista de vestuários e similares, baseado em empresas que se enquadram nestas duas classificações, sendo que a grande maioria (72\%) são classificadas como microempresas e somente $28 \%$ das empresas são enquadradas como empreendimentos de pequeno porte.
Gráfico 3 - Classificação das Empresas

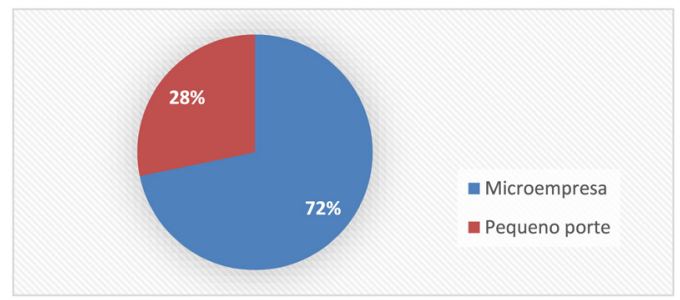

Ainda no intuito de conhecer a realidade das empresas varejistas da comunidade mercedense, foi questionado aos respondentes em que ramo de atividade elas atuam, ou seja, se atuavam somente como prestadoras de serviços e/ou também comercializam produtos, ou ainda, se somente comercializam produtos ou somente serviços.

Gráfico 4 - Ramo de atividade

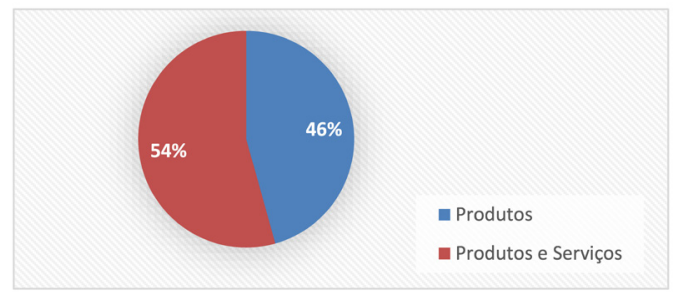

Com base nas respostas dos entrevistados, é possível observar, no gráfico 4, que pouco mais da metade das empresas varejistas atuam de forma conjunta, vendendo tanto produtos quanto serviços. Isto possibilita interpretar que, mesmo se caracterizando como empresas de varejo, estas atuam também no segmento de prestadores de serviços, no intuito de diversificar e abranger um pouco mais a sua atuação no mercado. Importante ressaltar que havia uma terceira opção na questão, indagando se a empresa mantinha atuação somente com serviços, contudo nenhuma empresa a selecionou.

De uma maneira mais específica, com vistas a compreender o ambiente de negócios atual, em meio à pandemia do COVID-19, 
questionou-se sobre o comportamento das vendas durante o período da crise.

Gráfico 5 - Faturamento Bruto

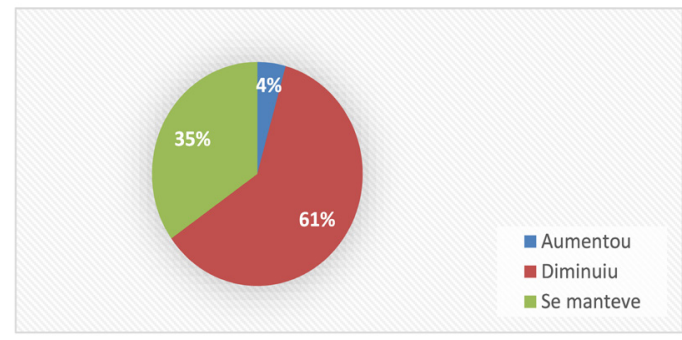

Conforme apontado no gráfico 5, a grande maioria dos entrevistados $(61 \%)$ relataram ter percebido um decréscimo no faturamento da empresa. Cerca de um terço das empresas conseguiram se manter estável diante da crise, enquanto uma pequena parcela (4\%) relatou aumento no seu faturamento.

Assim, pode-se analisar que, mesmo em meio a pandemia, algumas empresas conseguiram se sobressair e faturar mais do que em períodos normais. Isso, talvez possa ser justificado, por uma atuação mais direcionada ao comércio eletrônico ou emprego de estratégias diferenciadas na comercialização dos produtos, as quais alavancaram o negócio.

\section{Estratégias de marketing tradicional}

Nesta seção são apresentados de uma forma mais específica, os resultados obtidos em relação as estratégias de marketing tradicional utilizadas pelas empresas pesquisadas. Teoricamente, as estratégias de marketing são os meios e os métodos que a empresa utiliza para atingir seus objetivos.

Neste aspecto, foi perguntado aos entrevistados sobre a utilização de meios de publicidade tradicional, como televisão, rádio, jornal ou revista.
Gráfico 6 - Publicidade Tradicional

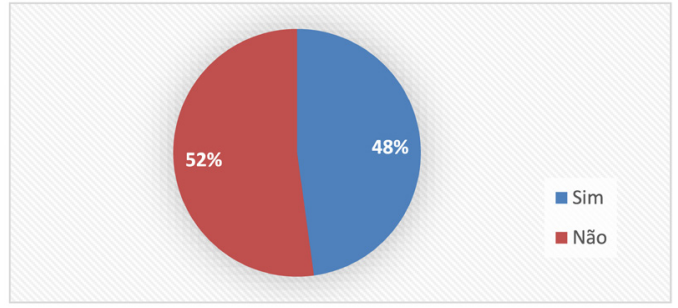

Os resultados da pesquisa apontam que $52 \%$ dos entrevistados não utilizam os meios tradicionais para a divulgação de sua empresa e seus produtos. Entretanto, outros $48 \%$ afirmaram fazer uso destes recursos, destacando assim, uma posição dividida entre as empresas que utilizam e aquelas que não utilizam estes meios de divulgação.

De forma contínua, buscou-se saber se as referidas empresas utilizam a internet como meio de vender aos clientes, bem como para a divulgação da empresa e dos seus produtos/ serviços.

Dentre as empresas pesquisadas, conforme se observa no gráfico 7 , apenas $30 \%$ efetivamente utilizam internet para vender aos seus clientes.

\section{Gráfico 7 - Uso de Internet}

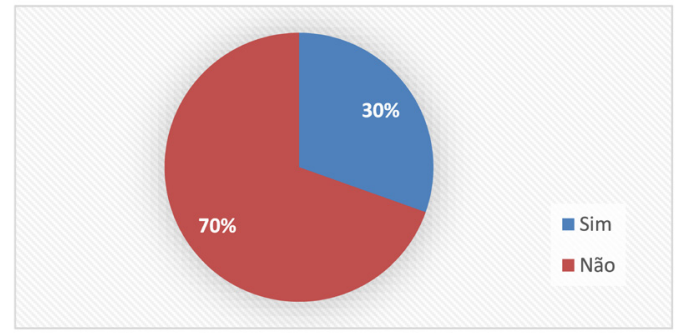

Deve-se ressaltar que a pesquisa em questão foi realizada, exclusivamente, com empresas que atuavam em estabelecimentos físicos. Sendo assim, é possível entender que mesmo com o atendimento presencial parcial dos seus clientes, em razão da pandemia, quase um terço dessas empresas atuaram também 
com vendas online durante a crise. Isso talvez possa explicar o crescimento do faturamento de algumas empresas durante a crise, enquanto a maioria obteve um decréscimo, ou seja, diante do fechamento total ou parcial do comércio via decreto oficial, aqueles que se reinventaram e possibilitaram novas formas de comercialização, possivelmente, podem ter auferido melhores resultados.

Com uma breve análise do gráfico 8 , fica evidente que somente a minoria das empresas hospedam tem um site próprio para divulgar seus produtos. Este fator pode ser decisivo para interpretar o gráfico anterior, em que a maioria das empresas optam por redes sociais gratuitas para divulgação.

\section{Gráfico 8 - SITE}

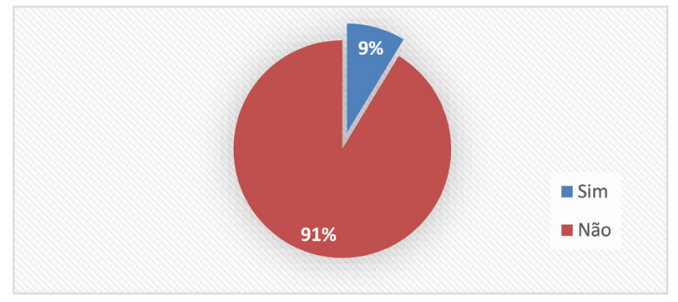

Pode-se entender desta forma que as empresas pesquisadas não possuem uma estrutura adequada para vendas online, o que pode ser determinante para incidir nos resultados obtidos no gráfico 7 , em que a maioria das empresas não efetuam vendas pela internet. De forma complementar também é possível associar aos resultados apresentados no gráfico 5, que trata sobre o faturamento das empresas no período pandêmico.

$\mathrm{Na}$ questão seguinte os entrevistados foram indagados sobre o uso de estratégias de marketing para divulgar sua marca, produtos e/ou serviços antes da pandemia do COVID-19.

Em análise do gráfico 9 fica claro que a maioria (67\%) das empresas se utilizavam de algum tipo de estratégias de marketing antes da pandemia começar, porém, um terço das empresas não utilizavam, o que é uma parcela considerável.

Gráfico 9 - Estratégia de Marketing antes da pandemia

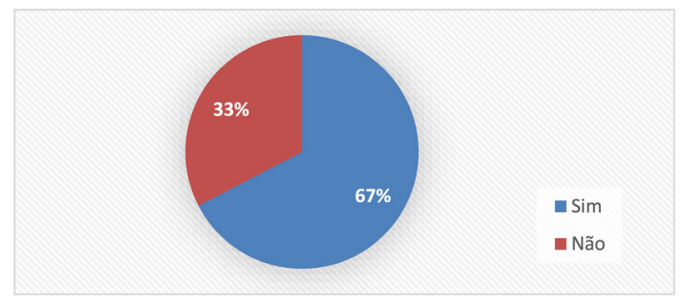

Na sequência foi indagado aos entrevistados sobre o uso de estratégias de marketing durante o período da pandemia, de março a julho, com o afastamento social. Conforme observa-se no gráfico 10 houve uma queda de $2 \%$ das empresas que utilizavam estratégias de marketing antes da pandemia, mas que deixaram de utilizar durante a pandemia. Isto indica que algumas empresas reduziram os investimentos em estratégias de marketing e divulgação de seus produtos no período do afastamento social, um momento considerado crucial para os negócios. Todavia, é notória essa reação por parte de empresários, dado o declínio do seu faturamento em momentos de crise.

Gráfico 10 - Estratégia de Marketing Durante a Pandemia

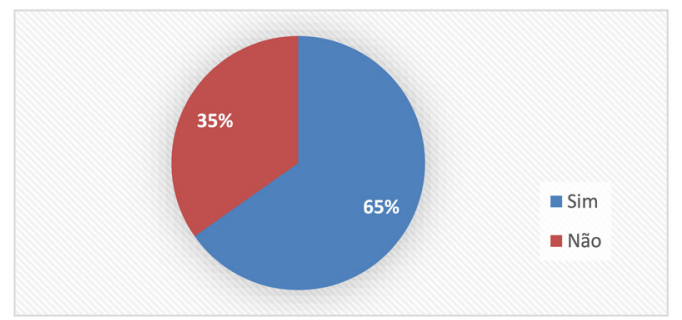

Por outro lado, geralmente, é nos momentos de crise que as empresas precisam se apresentar ao seu consumidor e reafirmar o seu compromisso de melhor atendê-lo e 
propor medidas capazes de manter a satisfação do cliente, seja por meio de promoções, estratégias menos onerosas em termos de divulgação, criatividade na gestão dos negócios que impliquem na redução dos custos e manutenção ou ampliação das margens de lucro. Acontecendo o contrário disso, os impactos negativos nos resultados da empresa são praticamente certos.

Neste sentido, o próximo tópico busca avaliar a implementação, por parte dos empresários, de medidas ou estratégias de marketing de guerrilha para o enfrentamento dos desafios impostos pela crise pandêmica, estratégias estas consideradas de baixo custo e de alto impacto mercadológico, quando comparada às estratégias tradicionais.

\section{Estratégias de marketing de guerrilha}

$\mathrm{O}$ uso de estratégias de marketing de guerrilha, objeto principal desta investigação, seguirá de forma rigorosa o que normalmente é aceito pela literatura geral e, principalmente, apresentada por Levinson (2010), que em seu argumento salienta que marqueteiros de guerrilha não confiam na força bruta de um orçamento gigantesco, porém são mais confiantes na força bruta da imaginação fértil e de baixo custo. Este mesmo autor defende que o melhor investimento é aquele feito em tempo, energia, imaginação e informação em vez de dinheiro (LEVINSON, 2007). Por outro lado, são abordadas as sete ferramentas mais importantes que qualificam de forma estratégica o marketing de guerrilha, na visão de Leite e Velhinho (2012).

A primeira ferramenta, trata-se do $\mathrm{Am}$ bush marketing ou Marketing de emboscada, ou seja, associando sua marca, seus produtos e/ou serviços a outras marcas, produtos e/ou serviços como estratégias de divulgação ou vendas.
Gráfico 11 - Ambush Marketing

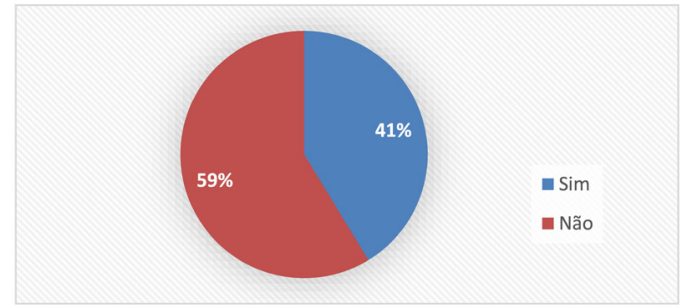

Tendo por base os resultados descritos no gráfico 11, é possível observar que a maior parte $(59 \%)$ das empresas pesquisadas afirmam que não associam suas marcas com outras marcas, mesmo que seja para fortalecer a notoriedade de sua própria marca, produtos e serviços.

Estudos realizados por Pinho (2012) destacam que em Portugal, observou-se uma grande disputa entre as marcas de cerveja Super Bock e Sagres. Relatos do autor apontam que em 2008, a Super Bock colocou na rua uma campanha com a expressão "Força Portugal" que configurava a prática de Ambush marketing, pois se tratava de uma associação indevida à seleção portuguesa de futebol, cujo patrocínio exclusivo pertencia à Sagres. A Sagres fez queixa no (ICAP), agência que regula a publicidade no país, entretanto, o instituto decidiu não dar provimento à queixa por considerar não haver violação da lei.

Quanto a segunda ferramenta, relacionada ao uso de Astroturfing, que consiste em se utilizar e/ou participar de ações em defesa de alguma causa comum, geralmente social, como por exemplo, crianças, velhos, gênero, animais, meio ambiente e outros, no entanto sem denotar que está incorporando ou divulgando sua marca, seus produtos ou serviços, verificou-se, conforme se observa no gráfico 12 , que $93 \%$ dos respondentes afirmaram não se utilizar de tal estratégia.

A grande maioria dos entrevistados tomam uma posição de neutralidade em atividades sociais relevantes da sociedade local, 
mesmo que possam se utilizar desse meio para divulgação de sua marca, seus produtos ou serviços.

Gráfico 12 - Astroturfing

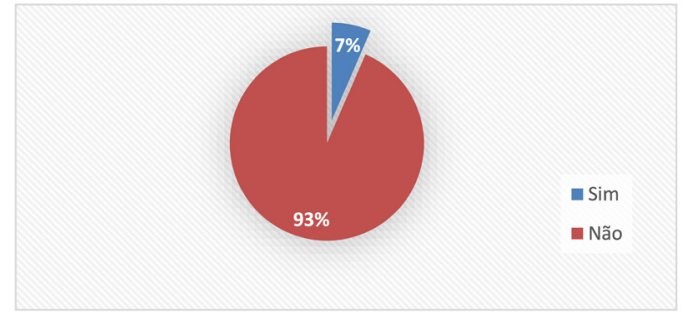

Em estudo realizado por Paupério (2018), descreve-se uma estratégia de Astroturfing, realizada em 2007, pela operadora de telefonia móvel Oi, juntamente com a campanha publicitária, lançaram o movimento "Bloqueio Não" em que a ideia era espalhar o movimento social de independência contra modelo de negócio adotado na época, em que os clientes ficavam presos a uma única operadora, sem poder migrar para a concorrência (fazer portabilidade) afim de obter vantagens competitivas, e levaram a população a ir contra os concorrentes gerando indignação e, consequentemente, trocarem de operadora. A estratégia foi lançada em um site totalmente focado no movimento em si e não havia qualquer menção à marca Oi, apenas havia uma nota em rodapé com a indicação de "Defendem esta causa" como uma empresa de apoio.

$\mathrm{Na}$ terceira ferramenta do marketing de guerrilha, apresenta-se o Buzz marketing. Esta estratégia visa a captar a atenção dos consumidores e da própria mídia utilizando-se muitas vezes de personagem com alguma notoriedade para se criar a chamada propaganda boca-a-boca.

Por se tratar de um município pequeno, é possível observar, no gráfico 13 , que o aspecto do marketing boca-a-boca é muito forte, quase $80 \%$ das empresas declararam fazer uso deste tipo estratégia para divulgação de sua marca, produtos e serviços. Não necessariamente relacionado a um personagem midiático, mas alguém que inspira confiança e possui notoriedade no município para inspirar, incentivar e persuadir novos clientes.

\section{Gráfico 13 - Buzz Marketing}

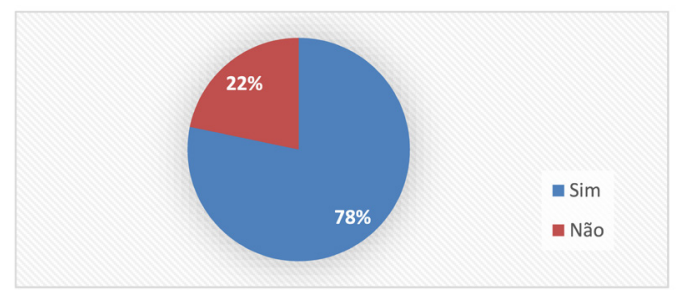

Este tipo de estratégia, geralmente, inicia-se com o envio de mensagens a determinados consumidores, líderes de grupos de referência, pessoas admiradas pelo grande público e muito sociáveis que, por sua vez, divulgarão a mensagem. Porém, nem sempre é fácil encontrar estes "lançadores" de tendências e motivá-los a falar do produto ao círculo de amigos, família e colegas (LEITE; VELHINHO, 2012).

Os autores supracitados afirmam que a Ford foi a pioneira na prática de Buzz marketing. No início dos anos 60 , a empresa atravessava uma fase complicada, pois havia perdido uma grande fatia do mercado e os consumidores achavam-na banal e desinteressante. Visando a recuperar o mercado perdido, a empresa concentrou-se numa criativa campanha de marketing com anúncios inovadores e engraçados que mantinham um certo mistério, um segredo que todos ficavam ansiosos para descobrir. Tratava-se da oferta de automóveis Mustang, envolvendo personalidades influentes, com o intuito de estas serem vistas conduzindo o veículo da Ford. As sementes do buzz estavam lançadas e criou-se uma histeria nacional. Milhares de automóveis foram vendidos no primeiro ano, e poderiam ter vendido muito mais se 
a capacidade da planta industrial permitisse. No segundo ano, a empresa vendeu mais de um milhão de veículos.

Ao considerar a quarta ferramenta, o Marketing invisível, foi investigado se as empresas utilizam formas de envolver o consumidor ao ponto que este não percebesse que se tratava de uma ação de marketing.

Gráfico 14 - Marketing Invisível

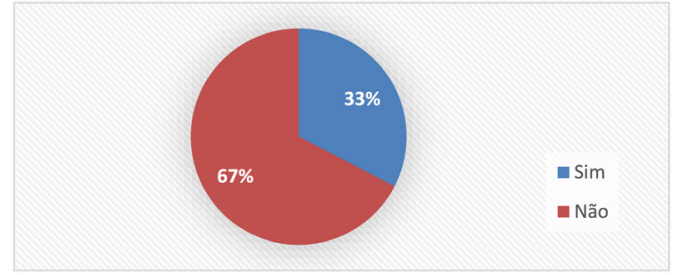

Neste aspecto, conforme evidenciado no gráfico 14 , apenas $33 \%$ das empresas afirmaram utilizar esta ferramenta. A grande maioria delas (67\%) não utilizam, conscientemente, ou quem sabe, nem sequer a conhecem.

Conforme argumentam Santos e Athaydes (2008), o público atingido por estas ações não tem consciência de que se trata de uma campanha publicitária e, por este motivo, não apresenta qualquer tipo de resistência, apresentando-se mais receptivos à informação sobre os produtos, serviços ou marcas das empresas que adotam este tipo de estratégia.

Um estudo realizado por Leite e Velhinho (2012) descreve uma prática de marketing invisível, na qual a empresa Junk Food, no sentido de proteger as crianças da promoção televisiva de alimentos não saudáveis e, salvaguardá-las da crescente epidemia de obesidade infantil, compromete-se a não exibir anúncios de alimentos e bebidas pouco saudáveis em horário nobre. Contudo, os seus produtos abandonaram a presença em formatos de publicidade tradicional, mas surgiram em programas de televisão em um formato de merchandising, com atores consumindo os produtos, por exemplo, o que para um consumidor pode não ser interpretado como uma propaganda do produto ou marca, mas serve para fixar a marca em sua mente e até mesmo estimular a compra.

A quinta ferramenta, notoriamente utilizada nas estratégias de guerrilha, trata-se de $P R$ Stunt, que consiste em usar a criatividade desenvolvendo produtos e/ou conteúdos impactantes para alcançar grande visibilidade e notoriedade, ou seja, é uma forma de associar sua marca.

\section{Gráfico 15 - PR Stunt}

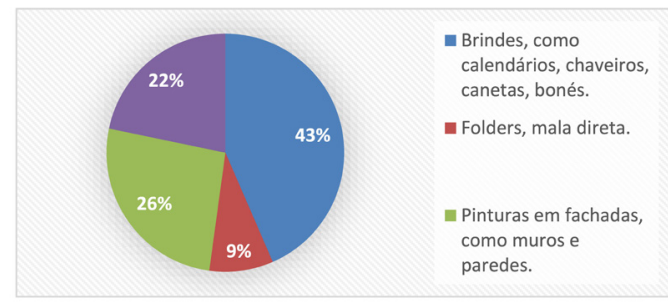

Os resultados colhidos nesta questão e apresentados no gráfico 15 , demonstram que quase a metade $(43 \%)$ das empresas pesquisadas, afirmaram que utilizam a estratégia de associar sua marca à distribuição de algum tipo de brinde ao consumidor. Outros $26 \%$ realizam ações de divulgação em pinturas em fachadas, e 22\% usam recursos de vídeos. Com pouca atuação, algumas empresas usam folders ou mala direta, alcançando somente $9 \%$ do total pesquisado.

Observou-se, também, que algumas estratégias apresentadas nas opções da pergunta não aparecem no gráfico, devido a nenhuma das empresas as ter selecionado. São elas: mobiliário urbano, como painel digital, triedro, outdoors, relógio de rua, termômetro, placas de esquina, placas de rua, faixas e adesivos para carros.

A sexta ferramenta, Ideavirus ou Marketing viral, tem a intenção de espalhar informações de forma rápida, que atinja o maior 
número possível de pessoas com conteúdo, muitas vezes divertidos, despertando o interesse dos consumidores a fim de contagiar outras pessoas, com a divulgação do seu produto ou serviço utilizando-se, principalmente, de meios eletrônicos como as redes sociais.

Conforme apresentado no gráfico 16, essa ferramenta é largamente utilizada, porém, com esta análise consegue-se observar que mesmo com tão poucas vendas efetivadas pela internet, (destaque para o gráfico 6), o uso do marketing viral é fator predominante nas empresas pesquisadas para divulgar seus produtos - quase $90 \%$ das empresas afirmaram fazer uso, em algum momento, desta estratégia, para atingir seu público, divulgando sua marca ou seus produtos.

Gráfico 16 - Marketing Viral

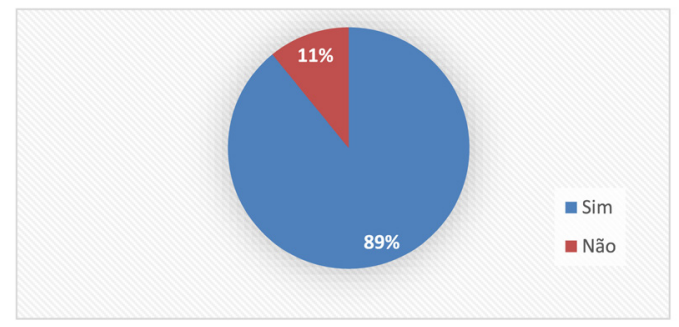

Na visão de Paupério (2018) essa é uma poderosa estratégia que espalha a mensagem que a marca quer transmitir sem cansar o consumidor. O campo de atuação da mensagem pode ser sites, blogs, redes sociais como o Facebook, Twitter ou Instagram. A mensagem deve ser forte e apelativa o bastante para que haja um interesse por parte dos internautas, estimulando-os a realizar a divulgação de forma a que a mensagem seja reproduzida diversas vezes e visualizada pelo maior número de pessoas possíveis.

A autora supracitada exemplifica uma aplicação de Marketing viral pela marca de cervejas Heineken que fez uma campanha, em 2016, conduzida na UEFA (Champions League) em que se aborda, precisamente, o clichê de que os homens tentam enganar as suas namoradas para poderem ir assistir à final do campeonato oferecendo-lhe uma ida ao spa. O desfecho do vídeo é surpreendente, pois as namoradas encontram-se no estádio, também para assistirem à grande final. A campanha teve mais de 4 milhões de visualizações em menos de 18 horas no Facebook, além de render imensa quantidade de comentários elogiosos, principalmente, por parte do público feminino que se sentiu representado na ação.

A sétima e última ferramenta do marketing de guerrilha, abordada neste estudo, trata-se do Performance, caracterizado pela promoção ou aproveitamento de um evento, principalmente público, tendo como objetivo, nessa estratégia, promover a interação entre a empresa e o público-alvo e, assim, transmitir uma mensagem em forma de entretenimento e criatividade.

\section{Gráfico 17 - Performance}

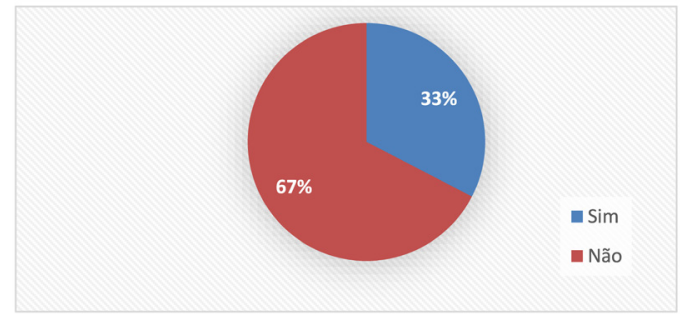

Os resultados da pesquisa apontam que a grande maioria (67\%) das empresas não utilizam essa ferramenta e, com isto, perdem uma oportunidade importante de divulgar sua marca ou produtos, inibindo as possibilidades de fazer parte do cotidiano das pessoas.

Em análise ao uso destas sete estratégias de marketing de guerrilha, observa-se que as empresas avaliadas fazem pouco uso das referidas ações, as quais poderiam causar grandes impactos em seus resultados, sem o dispêndio de um grande volume de recursos econômicos. 


\section{Considerações finais}

Em contextos gerais de aplicabilidade de estratégias de marketing tradicional em ações mercadológicas, apenas a metade das empresas pesquisadas alegaram fazer algum tipo de campanhas publicitária. Outra informação relevante é que a grande maioria (70\%) não utiliza internet para vender seus produtos ou divulgar sua marca e somente $9 \%$ possuem um site próprio. De forma complementar, em relação ao marketing de guerrilha, objeto central deste estudo, observou-se que, em média, $66 \%$ das empresas pesquisadas não fazem uso das principais ferramentas de marketing de guerrilha. Convém ressaltar que este tipo de ação é, justamente, a mais indicada para os pequenos negócios, que muitas vezes, por parcos recursos financeiros, não conseguem acessar ações de marketing tradicional.

Acredita-se que essa é a grande contribuição que este estudo deixa ao segmento de mercado pesquisado, pois fica evidente que, em primeiro lugar, deve-se conhecer a realidade existente, para em seguida compreender as novas estratégias de se fazer negócios, como o marketing de guerrilha e, a partir disso, quando passar a pandemia, tornar suas atividades mais produtivas e rentáveis, gerando divisas e melhor qualidade de vida aos munícipes.

Por fim, são apontadas algumas limitações desse estudo ao considerar que se trata de uma análise estática, utilizada num curto intervalo de tempo, de março a julho, abrangendo um pequeno segmento empresarial do ramo varejista de vestuários, numa situação jamais enfrentada, a pandemia do COVID-19. Entretanto, fica a recomendação de que os empresários do município, frequentemente, analisem suas ações de marketing no entendimento de que elas, aliada a outros meios, possa determinar a continuidade desses empreendimentos no futuro.

\section{REFERÊNCIAS}

BARBOSA, N. A. Arte, cultura, história. Rio de Janeiro: [s.n], 2007.

COBRA, M. Administração de Marketing. São Paulo: Atlas, 2010.

CRUZ, A. P. PR Stunt. Portal do Marketing, 2010. Disponível em: http://www.mktonline.net/index. php?cat=7\&kword=rp+stunt. Acesso em: 24 jun. 2020.

DANTAS, E. B. A propaganda de guerrilha: uma nova alternativa para posicionar marcas. Brasília, 2009. Disponível em: http://www.bocc.ubi.pt/pag/dantas-edmundo-a-propaganda-deguerrilha.pdf. Acesso em: 22 jun. 2020.

DIAS, S. R. Gestão de marketing. São Paulo: Saraiva, 2003.

DORNELAS, J. C. A. Empreendedorismo: transformando ideias em negócios. Rio de Janeiro: Campus, 2005.

FERRAREZI, G. Marketing tradicional ou marketing digital: quais são as diferenças? 2016. Disponível em: http://www.vnew.com.br/marketing-tradicional-ou-digital-quais-sao-as-diferencas. Acesso em: mar. 2020. 
FONSECA, H. P. M. Marketing Invisível: o discurso sedutor com rótulo de não persuasivo.

Universidade do Vale do Sapucaí. 2011. Disponível em: http://cienciasda4.dominiotemporario.com/ enelin/anais/texts/42.pdf. Acesso em: 24 jun. 2020.

FREIRE, M. V; ALMEIDA, D. R. Ouro olímpico: a história do marketing dos aros. Rio de Janeiro: Casa da Palavra: COB, 2006.

GIL, A. C. Como elaborar projetos de pesquisa. São Paulo: Atlas, 2009.

HILL, S.; RIFKIN, G. Marketing Radical. Lisboa: Editora Presença, 2002.

HUGHES, M. Buzz Marketing: faça passar palavra sobre os seus produtos e serviços. Lisboa: Actual Editora, 2006.

KARKOTLI, G. Marketing para iniciantes. Curitiba: Camões, 2008.

KOTLER, P. Marketing para Organizações que não visam o Lucro. São Paulo: Editora Atlas, 1988.

KOTLER, P.; KELLER, K. L. Administração de Marketing. Tradução: Monica Rosenberg, Brasil Ramos Fernandes, Claudia Freire. 12. ed. São Paulo: Pearson Prentice Hall, 2006.

LEITE, A. C.; VELHINHO, M. A importância e o contributo do marketing de guerrilha no sucesso das marcas, 2012. 133 p. Dissertação (Mestrado em Publicidade e Marketing) - Escola Superior de Comunicação Social, Instituto Politécnico de Lisboa, Lisboa, 2012.

LEVINSON, J. C. Marketing de Guerrilha: novas estratégias, tácticas e armas para obter grandes lucros no mundo empresarial de hoje. Lisboa: Difusão Cultural, 1989.

LEVINSON, J. C., LEVINSON, J., LEVINSON, A. Guerrilla Marketing: easy and inexpensive strategies for making big profits from your small business. 4th Ed. New York: Houghton Mifflin, 2007.

LEVINSON, J. C. Marketing de guerrilha: táticas e armas para obter grandes lucros com pequenas e médias empresas. Rio de Janeiro: Best Seller, 2010.

MATTAR, F. Pesquisa de marketing: metodologia e planejamento. 3. ed. São Paulo: Atlas. 1996.

PAUPÉRIO, B. F. Marketing de Guerrilha: uma chamada para a atenção e para a ação.

Dissertação de Mestrado em Ciências da Comunicação: Relações Públicas, Marketing e Publicidade. Universidade Fernando Pessoa, Porto. Portugal, 2018.

PINHO, G. Marketing de guerrilha: uma mais-valia para as marcas no mercado português. Dissertação (Mestrado em Gestão), ISCTE Business School. Instituto Universitário de Lisboa. Lisboa, Portugal, 2012.

PIRES, A. Marketing: conceitos, técnicas e problemas de gestão. Lisboa: Editora Verbo, 1995.

REIS, A. C. F. Marketing de emboscada: e depois de tudo, quem leva a culpa? Caderno de Pesquisa em Administração, São Paulo, v.1, n.2, 1996. Disponível em http://www.ead.fea.usp.br/Cad-pesq/arquivos/C02-art05.pdf. Acesso em: 24 jun. 2020.

RODRIGUES, C. M. Novas Estratégias Publicitarias na Conquista do Consumidor: o caso do Marketing de Guerrilha, 2010. Universidade Federal do Espírito Santo. Disponível em http://mba. americaeconomia.com/sites/mba.americaeconomia.com/files/tcccintiafinal.pdf. Acesso em: 24 jun. 2020.

ROESCH, S. M. A. Projetos de estágio e de pesquisa do curso de administração: guias para estágios, projetos e estágios e trabalho de conclusão de curso. São Paulo: Atlas, 1996.

SANTOS, J. M., ATHAYDES, A. A ética nas ações do Marketing de Guerrilha. In: IX Congresso de Ciências da Comunicação na Região Sul. Anais [...] Guarapuava, 2008. Disponível em: http://www. intercom.org.br/papers/regionais/sul2008/resumos/R10-0306-1.pdf. Acesso em: 27 jul. 2020. 
SEBRAE - Serviço Brasileiro de Apoio às Micro e Pequenas Empresas. Disponível em: https:// www.sebrae.com.br/sites/PortalSebrae/sebraeaz/lei-geral-completa-10-anos-e-beneficia-milhoes-deempresas,baebd455e8d08410VgnVCM2000003c74010aRCRD. Acesso em jun. 2020.

SILVA, S. M. da; SANTOS, C. C. M.; SIQUEIRA, J. de O. O uso do questionário eletrônico na pesquisa acadêmica: um caso de uso na Escola Politécnica da Universidade de São Paulo. In: II Semed - Seminários em Administração do Programa de Pós-Graduação em Administração da FEA/ USP, Anais [...], São Paulo, 1997, p. 408-421.

TEIXEIRA, E. B. A análise de dados na pesquisa científica: importância e desafios em estudos organizacionais. Desenvolvimento em questão, v. 1, n. 2, p. 177-201, 2003.

TZU, S. A Arte da Guerra. Lisboa: Texto Editores, 2011. 
